material without giving any impression of crowding or undue abbreviation. Except that he does not discuss measuring devices, he deals with nearly all the subject matter of the larger book and he includes a number of fully worked practical examples. Many of his methods differ from Mr. Wilson's, and the two books should be regarded as mutually complementary rather than as alternatives.

(3) Mr. Cole's book is of a different nature, being an introductory textbook on the general theory of those parts of the subject of vibrations that are important to engineers. The theories of free vibrations, with and without damping, and of forced vibrations are first dealt with. Engine vibrations, the elimination of vibration, the transverse vibrations of beams, and the whirling of shafts are then briefly discussed. The exposition is throughout very clear and is helped by a large number of excellent figures. Examples for practice are added at the ends of the principal sections, the answers being given. All engineering students with any mathematical ability would profit by using this book as a supplement to the chapters on vibrations in their textbooks of strength of materials and theory of machines, and many mature engineers might find it of value as an introduction to more specialised treatises and original papers.

\title{
The Reptiles of China
}

\section{The Reptiles of China:}

Turtles, Crocodilians, Snakes, Lizards. By Clifford H. Pope. (Central Asiatic Expeditions: Natural History of Central Asia, Vol. 10.) Pp. lii +604 +27 plates. (New York: American Museum of Natural History and G. P. Putnam's Sons; London: G. P. Putnam's Sons, 1935.) 10 dollars.

$\mathrm{M}^{\mathrm{R}}$ R. POPE'S "Reptiles of China" is the outcome of some fourteen years of continuous study. Four of these were spent in the field collecting and observing, the remainder in a more detailed study of his material in New York, and a comparison of it with the collections already existing in the other great museums of the world. No complete survey of this large area has been attempted before, and herpetologists will be grateful to Mr. Pope for having collected, examined and arranged the mass of material and literature relating to the subject which is now available.

The area dealt with is China south of a line connecting the northern extremity of the Gulf of Liaotung with the northernmost point of Kansu Province. This, although the author does not say so, is, roughly speaking, China south of the Great Wall, together with the eastern part of Tibet; the Island of Hainan is included but not Formosa. The bulk of the volume, pp. 19-453, is given up to the account of the Chelonians (22 species), the Crocodilians (I species) and Snakes (130 species and subspecies); while the Lizards (65 species, pp. 457-487) are condensed into an annotated check list, with keys for their identification.

The descriptions, although short, are generally sufficient for their purpose. For the first time in any large textbook, we have details of the sexual variation in snakes and of their penial characters. That the latter have considerable specific value cannot now be doubted, although their full taxonomic importance can only be assessed when we have a wider knowledge of them. Habits also, in so far as they are known, are fully recorded. The field-naturalist will welcome these, but to the museum worker they have also a value, although at present he is inclined to ignore them. The mental 'make-up' of reptiles, as shown by their mode of life, has scarcely yet been studied, but it is evident that certain habits are confined to certain groups and, in their way, are as distinctive of the group as morphological characters. When they can be properly interpreted and correlated, they will have a significance which the taxonomist cannot afford to ignore.

On the other hand, the descriptions as regards external morphological characters, particularly those relating to the generic diagnoses, appear sometimes too brief. This is a pity, for a work of this magnitude, although intended primarily as a means of identifying the species, would have been so much more valuable had it included also that general anatomy which forms the basis of our classification and upon which the identifications depend. Without a knowledge of the generic characters also, it will be difficult sometimes to place a species new to science, or one new to the country and not mentioned in the work.

The volume is well illustrated; most of the text figures are new. There is a map, and a list of localities where collections have been made; these are all properly fixed as regards their geographical positions, a very necessary procedure for a region that is so little known. The bibliography includes all the available literature up to 1934. Mr. Pope has spared no pains to make his work as complete as possible; he is to be heartily congratulated on the result.
M. A. S. 